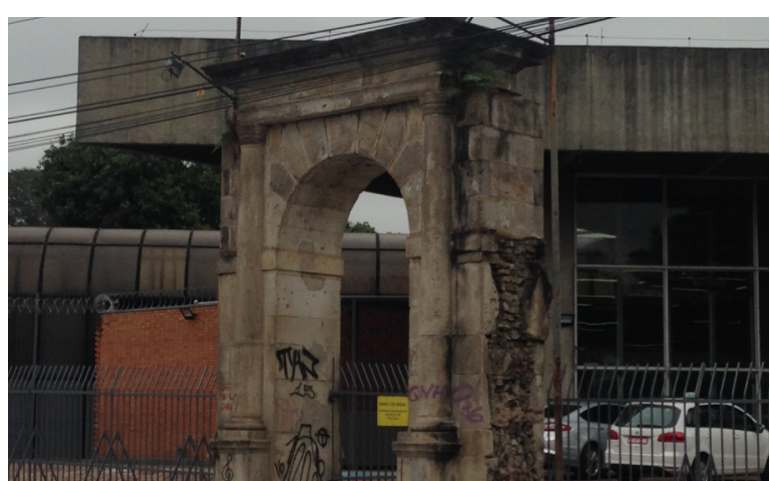

*Mestre pelo Programa de Pós-Graduação Stricto Sensu em Arquitetura e Urbanismo da Universidade São Judas. Arquiteta pela Universidade São Judas Tadeu (2016).

**Docente do Programa de Pós-Graduação Stricto Sensu e do Curso de Graduação em Arquitetura e Urbanismo da Universidade São Judas Tadeu. Doutora pela
FAU-USP (2004), Mestre pela Universidad Autónoma de Madrid (1991), Arquiteta pela Universidade Mackenzie (1985). Trabalhou com políticas públicas na Prefeitura Municipal de São Paulo, nas áreas de preservação do patrimônio e de desenvolvimento urbano. Líder do Grupo de Pesquisa "Patrimônio Cultural e Urbanismo: discursos e práticas", certificado pelo CNPq.

\title{
Lugares de memória difícil em São Paulo: reconhecimento de valor nas políticas de preservação do patrimônio cultural
}

\section{Sites of Hurtful Memory in São Paulo: recognition of value in polices of} cultural heritage conservation.

Mariana Busson Machado e Silva* e Andréa de Oliveira Tourinho**

\section{Resumo}

As memórias difíceis, relacionadas a situações violentas - conflitos, catástrofes naturais ou não - que geram sentimentos negativos e indeléveis em um determinado grupo social, têm sido, de forma crescente, objeto de discussões e estudos. No Brasil, as memórias difíceis ou traumáticas, como têm sido chamadas, começam a ganhar visibilidade na década de 1980, pós-ditadura militar, sendo objeto de interesse de várias áreas do conhecimento. Mais recentemente, há uma tendência de ampliação dos estudos sobre essa temática no campo da preservação do patrimônio cultural, porém a abordagem ainda é pouco explorada. O presente artigo trata do reconhecimento dos lugares de memória difícil, relacionados ao período militar, pelos órgãos de preservação na cidade de São Paulo, buscando identificar os valores a eles atribuídos.

Palavras-chave: Memória social. Tombamento. Políticas públicas. Órgãos de preservação.

\section{Abstract}

Difficult memories, related to shocking situations - conflicts, natural or unnatural catastrophes that generate negative and indelible feelings in a particular social group, have been increasingly subject to discussions and studies. In Brazil, the difficult or traumatic memories, as they have been called, began to gain visibility in the 1980s, post-military dictatorship, being an object of interest in several areas of knowledge. Recently, there is a tendency to expand studies on this subject in the field of cultural heritage conservation, but the approach is still little explored. This article deals with the recognition of difficult memory places related to the military period by the preservation agencies in the city of São Paulo, seeking to identify the values attributed to them.

Keywords: Social Memory. Heritage-listed buildings. Public Policy. Heritage conservation agencies. 


\section{Memórias difíceis e lugares de memória}

Desde a década de 1960, o conceito de patrimônio cultural vem se ampliando, a partir de mudanças sociais significativas, que se refletiram nos valores de memória e história. Essa ampliação manifestou-se na expansão do campo tipológico, cronológico e geográfico no qual se inscrevem os monumentos históricos (CHOAY, 2001), além de abarcar novos temas de discussão, expressos, entre outros, em conceitos tais

1. Na década de 1970, nouvelle histoire passou a denominar um movimento de renovação da historiografia desenvolvido pela terceira geração de historiadores franceses, entre os quais Jacques Le Goff e Pierre Nora, herdeira da Escola dos Annales, que na década de 1930 iniciara a renovação da abordagem histórica. A nouvelle histoire valorizou o indivíduo, a subjetividade e as representações simbólicas como elementos do conheci- mento histórico; desse modo valorizou as abordagens da história da cultura e das mentalidades e novos temas na construção do conhecimento sobre o passado.

2. Nora dirigiu a publicação de Les Lieux de mémoire, Paris, Gallimard (Bibliothèque illustrée des histoires), 3 tomos: t. $1^{\circ}$ La République $(1$ vol., 1984), t. $2^{\circ}$ La Nation (3 vol., 1987), t. $3^{\circ}$ Les France (3 vol., 1994). como os de paisagem cultural, patrimônio imaterial, memórias difíceis ou traumáticas.

Em relação a essa última categoria, afirma Ulpiano Bezerra de Meneses (2018) que, atualmente, há uma presença forte de museus e monumentos que se referem à memória traumática, como o Museu do Holocausto na Alemanha e o Memorial da Resistência no Brasil, ambos associados ao passado de injustiças e violências sociais, definindo-a nos seguintes termos:
A memória traumática é a face de maior força em nossos tempos, herança de conflitos e violências que assolaram o século passado e não desapareceram neste, sem contar os desastres naturais. O trauma cultural é aqui tomado, um pouco na linha de Neil Alexander, como a memória aceita por uma comunidade $e$ evocando evento ou situação carregada de afeto negativo, tida como indelével ou ameaçando seus valores e trazendo perturbações pela dificuldade de assimilação e horizonte final. (MENESES, 2018, p. 4)

Os acontecimentos que geram trauma ganham visibilidade com suas narrativas de denúncia em relação a crimes do passado e com o crescimento da violência nas sociedades atuais. Ainda de acordo com Meneses (2018), a partir da memória do trauma, novos conceitos foram surgindo e outros reestudados: a pós-memória (não vivida, mas absorvida por sentimento de empatia), a memória silente (do corpo), a memória ausente (aquela que existe, mas que por questões sociais 
é impedida de circular), a memória transgeracional (relacionada às gerações e que se transforma com o passar do tempo), entre outras.

Tais classificações não excluem a conhecida relação entre os lugares e a possibilidade de lembrar. Toda memória está relacionada a um acontecimento que ocorreu em algum lugar, ideia essa expressa no conceito "lugares de memória" por meio do qual o historiador, representante da nouvelle histoire ${ }^{1}$, Pierre Nora explicita as relações entre lugares e objetos, a partir de questionamentos sobre a construção da memória nacional na França². A ideia de "lugares de memória" aplica-se também ao campo das memórias dolorosas, que, de acordo com Renato Cymbalista (2017), revelam dilemas estruturais da sociedade, como os de gênero, raça, tolerância, minorias étnicas, violações de direito, abusos do poder do Estado e desigualdades sociais, entre outros. Esses dilemas ultrapassam gerações e os eventos a eles relacionados, ocorridos no passado, e repercutem no presente na forma de memória, ainda que em situações diversas e carregados de novos significados.

Os lugares de memória são testemunhos materiais da história e têm a força de nos transportar a tempos pretéritos, ainda que esses não tenham sido nossa experiência vivida, mas apenas transmitidas por meio de relatos de terceiros. Neles temos a percepção do "espírito do lugar", de sua especificidade e identidade, o que possibilita que os entendamos e os classifiquemos na hierarquia de nossos afetos, ressignificando-os, ainda que restritamente, apenas no campo individual. Ampliamos, assim, as possibilidades de reinterpretarmos o presente enquanto fruto de escolhas da sociedade limitadas às opções políticas dos segmentos que a compõem.

A importância dos "lugares de memória" para o contínuo processo de redefinição simbólica da sociedade - quer no âmbito individual, quer coletivo -, implica o reconhecimento de seus valores culturais pelo poder público. No caso de lugares relacionados a memórias traumáticas, as questões de proteção passam inicialmente pelo reconhecimento da existência do fato que as gerou, como no caso da história recente de nosso país, a existência da tortura como prática do Estado. Trata-se de uma questão iminentemente política, relacionada ao exercício pleno da democracia, que se completa com a análise dos órgãos de preservação, voltada mais aos significados sociais e valores éticos relacionados ao lugar do que para suas qualidades materiais.

De acordo com Meneses (2018, p. 5), as memórias traumáticas acirram o "conflito entre o dever de lembrar o direito de esquecer", cuja "questão fundamental é colocada por Ferenczi: é possível a memória justa? O que (e quando e como) é mais legítimo: reabrir as feridas ou dar a volta por cima?". Em seguida, na busca de respostas, o autor estabelece como consenso a ideia de que 
3. Ver a coletânea História dos crimes e da violência no Brasil, organizada pelas historiadoras Mary Del Priore e Angélica Müller, que reúne textos, sobre o tema, de autores de distintas áreas do conhecimento (São Paulo: Unesp, 2015). o direito à memória não pode sofrer restrições e que os indivíduos têm direito à História, o que remete a outro consenso, por ele também explicitado: "o esquecimento sem justiça afeta não só o presente, mas o futuro" (MENESES, 2018, p. 5).

$\mathrm{Na}$ sociedade brasileira, observa o mesmo autor, tendemos a não ter empatia com o passado que não vivenciamos, o que torna primordial o papel do pós-memória, aquela que, mesmo não vivida, é transmitida por terceiros e absorvida no âmbito familiar. Nesse sentido, museus, memoriais e testemunhos se tornam essenciais à ressignificação do presente por meio da memória, que informa e suscita o exercício da alteridade. Também é Meneses (2018, p. 14) que nos esclarece sobre a importância das instituições de memória como elo entre o presente e o passado:

[...] além de denunciar as enormidades da violência do passado, os museus comprometidos com os direitos humanos precisam assumir-se como faróis que iluminam também a violência de hoje, a violência cotidiana, a violência em qualquer modalidade e escala [...] no museu, a violência não seria mais uma noção abstrata: é coisa concreta, sensível, apreendida com nossos sentidos, nosso corpo e nossa mente [...] ilumina aquele caminho que podemos percorrer.

Neste cenário, a memória se evidencia como um campo de justiça, de denúncia, pesquisa e investigação. A sociedade brasileira é violenta e tem uma história enraizada em passados de escravidão, perseguição aos indígenas, tortura, entre outros aspectos, como vários autores ${ }^{3}$ já apontaram. Diante dessas constatações, colocam-se questões importantes para a reflexão sobre como lidar com lugares de memórias difíceis no campo do patrimônio cultural: em que momento aqueles passados ganharam maior visibilidade e reconhecimento? Como a memória do trauma está sendo discutida no âmbito do patrimônio?

No Brasil, as memórias difíceis ou traumáticas, como têm sido chamadas, começam a ganhar visibilidade na década de 1980, no período pós-ditadura militar, sendo objeto de interesse de várias áreas do conhecimento. Mais recentemente, há uma tendência de ampliação dos estudos sobre essa temática no campo da preservação do patrimônio cultural, porém a abordagem ainda é pouco explorada.

O presente artigo trata do reconhecimento dos lugares de memória difícil, relacionados ao período militar, pelos órgãos de preservação na cidade de São Paulo, buscando identificar os valores a eles atribuídos. Busca, dessa forma, registrar aspectos da forma pela qual as memórias difíceis, desde a década de 1980, vêm sendo integradas às pautas de proteção ao patrimônio cultural, tomando como recorte temático e espacial os lugares de memória difícil relacionados à violência de regimes opressores, localizados na cidade de São Paulo, e o seu reconhecimento no período de democratização imediato ao fim da ditadura militar de 1964, em que essa discussão ganha destaque. 
Memórias difíceis e o direito à verdade chegam no Brasil

Na América Latina, a temática das memórias difíceis ou traumáticas, em geral, vincula-se ao âmbito dos regimes autoritários ocorridos nesses países entre as décadas de 1960 e 1980. É a partir da década de 1980, no contexto da redemocratização, que ganham destaque as discussões acerca de crimes de tortura, violações aos direitos humanos e abusos do poder do Estado.

De acordo com Cymbalista (2017), primeiramente houve um movimento de reconstrução da sociedade pós-trauma que parecia pouco interessada em lembrar do passado de dor, de suas narrativas e de locais que remetessem à ditadura. Naquele momento, havia também uma preocupação com o cenário político que deveria ser redefinido e uma ansiedade comum diante das mudanças que ocorriam no mundo.

Sob outra perspectiva, surgiu um processo embrionário de certos grupos sociais que pretendiam enfrentar os conflitos do passado, principalmente os familiares de ex-presos políticos que buscavam justiça. Procuravam, na investigação de um passado recente de dor, esclarecer as questões que o envolviam, pois precisavam de medidas judiciais que os amparassem e que vingassem a morte de seus entes queridos.
No período de redemocratização pós-ditadura militar foi adotada a chamada justiça de transição, ou seja, um conjunto de medidas judiciais que tinham como intuito reparar violações aos direitos humanos e estabelecer mecanismos para responsabilizar o Estado sobre os crimes cometidos durante regime militar. De acordo com Miranda e Melo (2018, s/p), em artigo sobre o direito à verdade, existem quatro obrigações do Estado visando à efetividade da justiça de transição:

[...] adotar medidas razoáveis para prevenir violações de direitos humanos; oferecer mecanismos e instrumentos que permitam a elucidação de situações de violência; dispor de aparato legal que possibilite a responsabilização dos agentes que tenham praticado as violações e; garantir a reparação das vítimas, por meio de ações que visem à reparação material e simbólica.

No Brasil, os algozes responsáveis pelas atrocidades da repressão saíram ilesos e sem julgamento. O país foi palco, contudo, de algumas ações e experiências que contribuíam para o movimento de luta contra os opressores da ditadura militar e os primeiros passos para o processo de redemocratização. Abordaremos, de forma breve, algumas dessas iniciativas que mudaram a forma da sociedade olhar para o passado. 


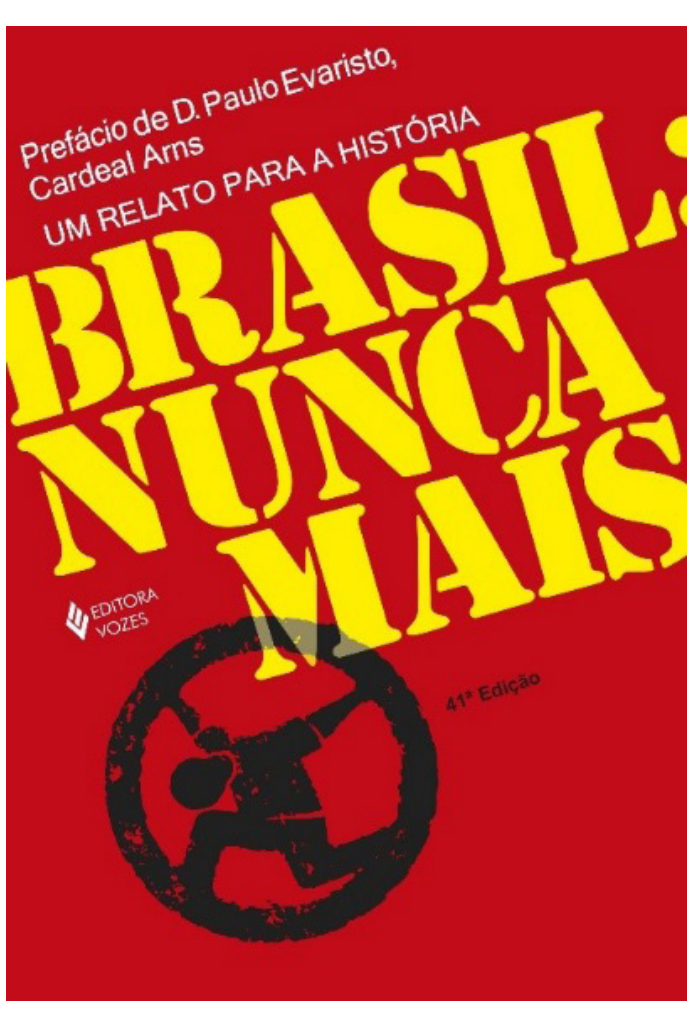

Figura 1. Capa do livro Brasil: Nunca Mais. Fonte: Acervo dos Autores.
A Lei da Anistia foi promulgada em 1979, no governo de João Baptista Figueiredo, depois de grande mobilização social, e tinha o intuito de reparar punições aos brasileiros que, entre os anos de 1961 e 1979, foram considerados presos políticos, concedendo-lhes anistia pelos crimes cometidos. A lei foi importante pois permitiu que os familiares das vítimas e os exilados voltassem ao país, e incentivou o processo de abertura política. Porém, pelo fato de não responsabilizar e penalizar os perpretadores dos crimes cometidos, a anistia acabou por nivelar vítimas e algozes.

A publicação do livro Brasil: Nunca Mais (Figura 1), em 1985 - quatro meses depois da retomada do regime civil no país -, promovida pela Arquidiocese de São Paulo e idealizada pelo arcebispo Dom Evaristo Arns, é considerada uma das ações mais marcantes no movimento de voz e luta contra os crimes da ditadura militar. O livro foi elaborado pela iniciativa de advogados de ex-presos políticos, além de historiadores e jornalistas interessados em estudar o passado de repressão. Lançado em 1985, o documento descreve de maneira contundente os diversos métodos de tortura utilizados no regime militar, a partir da seleção de processos da Justiça Militar que comprovam os crimes cometidos desde 1964:

[...] que, no dia 8 de outubro, na P.E. 1, posto de Segurança Nacional, quando era ministrada uma aula, na presença de mais de cem pessoas foram trazidos para aquela aula companheiros e, nesta ocasião, passaram filmes de fatos relacionados com torturas e em seguida era confirmada com a presença do denunciado, sendo, naquela ocasião também, torturados; ocasião esta coincidente com seu depoimento; que estas torturas, ou seja, as acima descritas, se repetiram na Vila Militar. (LEITE, 1970 apud ARNS et al., 1985, p.33)

O livro representa um avanço na construção de uma consciência coletiva acerca do que realmente foi a ditadura e, a partir da narrativa de torturados, possibilitou que a sociedade tivesse direito à verdade, apresentando provas da ação de terrorismo do Estado. Os relatos explícitos chocam os seus leitores, inclusive os que não foram protagonistas daquela época, gerando um sentimento de empatia diante de tanta crueldade.

Hoje, mais de trinta anos depois do regime militar, o documento ainda gera revolta e é utilizado como ação educativa e de prevenção, para evitar que fatos como esses se repitam, tendo sido considerado um obstáculo para aqueles que tinham o intuito de apagar o passado, "abrindo os olhos" da sociedade que precisava entender o tar de Inquéritos Perus - Desaparecidos Políticos (CPI-Perus) na Câmara Municipal de São Paulo. A repercussão dessas descobertas mais uma vez impactou a sociedade e instigou os familiares dos ex-presos políticos a denunciarem o ocorrido e despertaram esperança naqueles que queriam encontrar os corpos de seus parentes. 


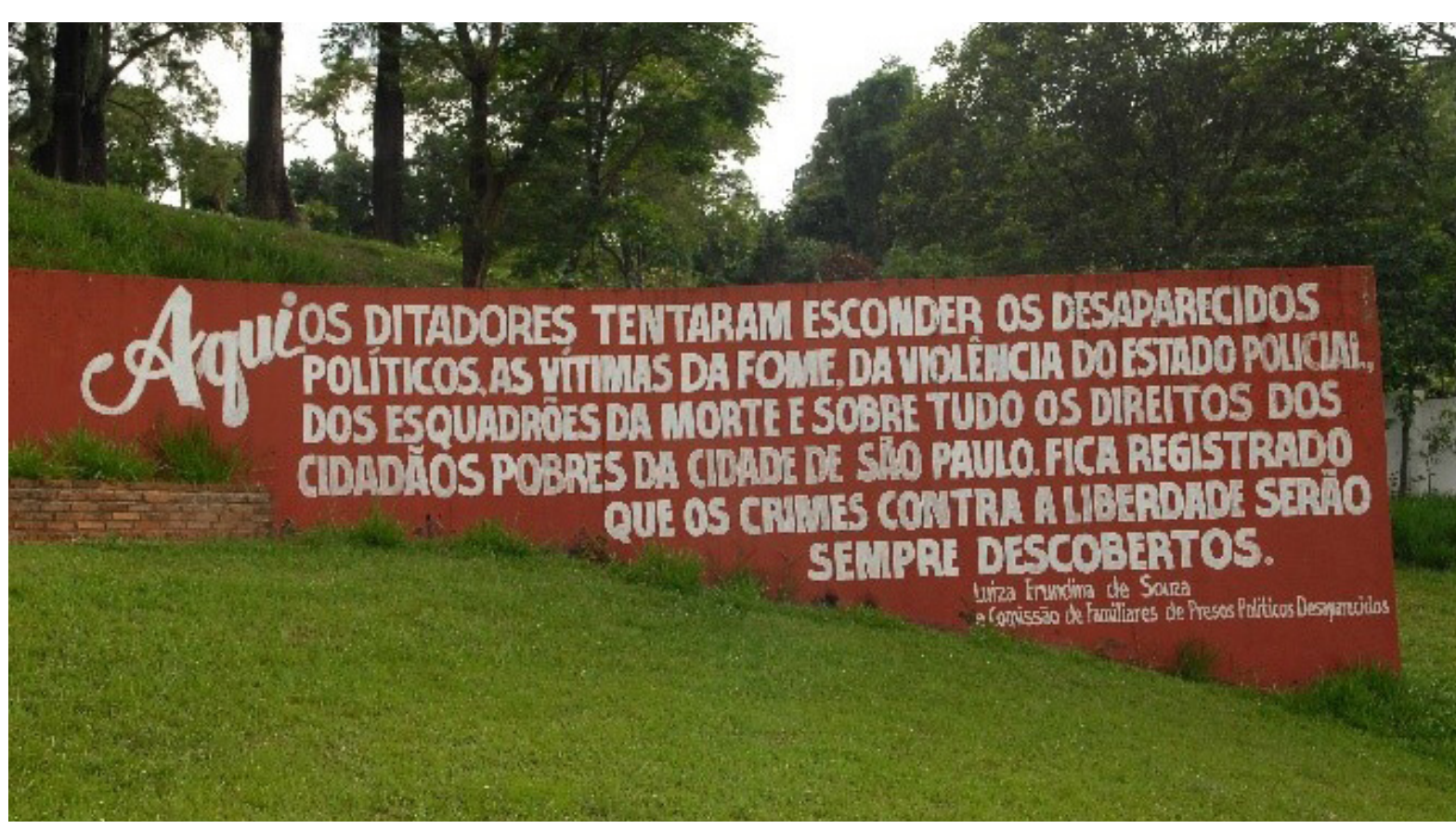

Figura 2. Memorial da Vala de Perus, s/d. Fonte: Acervo dos Autores.

4. Publicação com o apoio

do Governo Federal do Bra-

sil, Instituto Macuco, Projeto

Marcas da Memória, Comis-

são da Anistia e Ministério da

Justiça.
As escavações ocorreram juntamente com o Instituo Médico Legal (IML), possibilitando encontrar mais provas da atuação clandestina. Em 1991, o Estado promulgou a Lei dos Mortos e Desaparecidos Políticos e, em 1995, foi criada a Comissão dos Direitos Humanos do Congresso Nacional. Em 2012, foi publicado o livro Vala Clandestina de Perus. Desaparecidos Políticos um capítulo não encerrado da História Brasileira ${ }^{4}$, que tinha o intuito de servir como fonte de informações, pesquisa e estudo de um período que não deve ser esquecido, o direito à verdade se manifestava mais uma vez através desta documentação.
Em 1993, foi inaugurada pela então prefeita Luiza Erundina, junto à Comissão de Familiares de Presos Políticos Desaparecidos, um memorial em homenagem às vítimas enterradas no Cemitério de Perus (Figura 2).

Também na década de 1990, foi criada a Comissão dos Mortos e Desaparecidos com o objetivo de buscar e identificar restos mortais de mortos e desaparecidos políticos nos estados do Pará e Tocantins, devido à Guerrilha do Araguaia, no estado de São Paulo, na "Vala Clandestina de Perus", e, no estado do Rio de Janeiro, acompanhar pesquisas relacionadas à chamada "Casa da Morte", centro clandestino de detenção e tortura no município de Petrópolis. Essa Comissão continua atuando na investigação e na tentativa de reconhecimento de ossadas, tendo sido feitas duas descobertas, desde 2014, de ossadas de militantes mortos durante o regime militar. Seus parentes reuniram-se em Brasília e receberam atestados de óbito com a mudança da causa da morte que ocorreu em razão da ditadura militar, mostrando a luta dos familiares que ainda seguem em busca da verdade.

Nos anos 2000, a publicação do livro "O Direito à Memória e à Verdade", publicado em 2007 pela Secretaria Especial dos Direitos Humanos da Presidência da República, foi outra iniciativa de resgate da justiça, memória e verdade. A publicação apresenta histórias de diversos militantes, vítimas e desaparecidos no período de 1961 
a 1988, estudados caso a caso com o intuito de se avançar no debate sobre os direitos humanos e homenagear as vítimas das brutalidades do regime ditatorial.

Instaurada em 16 de maio de 2012, de acordo com a lei federal $n^{\circ} 12.528 / 2011$, a Comissão Nacional da Verdade foi mais um dos avanços recentes relacionados ao debate sobre a memória da ditadura. Durante o governo de Dilma Roussef, a comissão foi criada para investigar, por meio de depoimentos de vítimas e testemunhas, as violações de direitos humanos pelo Estado ou por conflitos armados, no período ditatorial com o objetivo de reparar as famílias dos militantes mortos ou desaparecidos.

Como fica evidente, mesmo após cerca de 55 anos do golpe que iniciou o regime militar, o debate sobre esse passado ainda é recente. Ainda existem corpos sem reconhecimento e famílias que em busca da verdade, memória e justiça.

\section{Políticas públicas de preservação: novas perspectivas}

As recentes políticas de preservação do patrimônio cultural foram fortemente marcadas pelas mudanças dos valores culturais ocorridas no Ocidente após a Segunda Guerra Mundial (19391945).
As violentas destruições e mortes relacionadas a esse evento, bem como o uso de armas nucleares colocaram em xeque os valores de uma modernidade que acreditava, desde o Renascimento, na técnica e no progresso. Essa guerra foi considerada uma das mais letais da história da humanidade, atingindo diversos países e algumas comunidades em particular, como as dos judeus, vítimas de perseguição e genocídio em massa.

No pós-guerra, a Alemanha ficou estigmatizada como o país e o povo que produziram o holocausto, ficando marcada por esse evento traumático, ligado ao nazismo e a posterior divisão do país e o domínio da União Soviética na parte leste do território. O final deste período assistiu, por um lado, a tentativas de esquecimento do que havia acontecido e reconstrução do que tinha sido destruído, e, por outro, a um movimento de profunda reflexão sobre as atrocidades cometidas durante o conflito.

O mundo mudou muito desde então, passando pela chamada "era de ouro" e o seu final na década de 1970, as ditaduras da América Latina, a contracultura e a emergência de movimentos sociais relacionados aos direitos humanos, feminismo e ambientalismo, o colapso do mundo socialista, a revolução da tecnologia da informação, a globalização, as guerras do Oriente Médio, entre outros. Essas mudanças influenciaram as formas de olhar para o passado. 
De acordo com Meneses (2018), a segunda metade do século XX é marcada pelo interesse no estudo do passado como herança cultural para construção de um futuro mais democrático. Huyssen (2000, p. 9) afirma que vivemos um "boom memorialístico" caracterizado pela "emergência da memória como uma das preocupações culturais e políticas das sociedades ocidentais". Também Nora $(2009$, p. 6) ressalta esse aspecto:

[...] estamos experimentando a emergência da memória [...] é como uma onda de recordação que se espalhou através do mundo e que, em toda a parte, liga firmemente a lealdade ao passado - real ou imaginário - e a sensação de pertencimento, consciência coletiva e autoconsciência. Memória e identidade.

No Brasil, esse período é representado pela introdução cada vez maior de grupos antes marginalizados e excluídos nas questões relacionadas ao passado. A memória passa a ser vetor importante de identidade de grupos sociais, no processo de redemocratização e na luta pelos direitos sociais.

A Constituição Federal de 1988 foi inovadora nessa direção, reconhecendo o patrimônio cultural como valor produzido pela sociedade em sua pluralidade:

[...] o conceito de patrimônio se transformaria e ampliaria, bem como se transformariam o valor atribuído à memória pela sociedade, e as próprias formas de proteção do poder público. $\mathrm{O}$ termo histórico-arquitetônico, antes amplamente utilizado para qualificar o patrimônio, seria substituído por cultural; o universo de bens protegidos não se restringiria ao que é material, mas abrangeria as manifestações intangíveis, como as devoções e os fazeres. (RODRIGUES, 2009, s.p.)

Não apenas se verifica essa ampliação do conceito de patrimônio, mas se passa a falar em direitos culturais e no papel do Estado na garantia desses direitos: "o Estado protegerá as manifestações das culturas populares, indígenas e afro-brasileiras, e das de outros grupos participantes do processo civilizatório nacional" (BRASIL, 1988, Art. 215).

No universo dos direitos culturais, o direito à memória começava a aparecer nos discursos também dos órgãos oficiais de preservação do patrimônio. Em 1991, o Departamento do Patrimônio Histórico (DPH), ligado à Secretaria Municipal de Cultura da cidade de São Paulo, promove o Congresso "Patrimônio Histórico e Cidadania - O Direito à Memória", com a deliberação de um documento final, em que se destaca a importância do "direito à memória", que deve ser considerada de forma efetiva nas políticas de preservação, e da participação popular nas políticas públicas de memória.

Destaque-se, ainda, no referido documento, a ideia de democracia relacionada à memória, uma noção possível apenas com a abertura política do país: 
12. As ações voltadas para a preservação das cidades devem extrapolar o perímetro físico dos chamados centros históricos. A cidade, como resultado das ações humanas no passado e no presente, é sempre histórica. Assim, a política de preservação deve contemplar a convivência democrática entre o passado e 0 presente, entre os aspectos arquitetônicos, urbanísticos, sociais e culturais das experiências humanas nas cidades, em detrimento de monumentos isolados que, quase sempre, são reiteradores de uma memória oficial. (DPH, 1992, p. 231)

Direitos, democracia, participação popular são expressões que, a partir da década de 1980, entram no repertório do campo da preservação do patrimônio, sendo enfatizada a atuação compartilhada entre poder público e sociedade:

O poder público, com a colaboração da comunidade, promoverá e protegerá o patrimônio cultural brasileiro, por meio de inventários, registros, vigilância, tombamento e desapropriação, e outras formas de acautelamento e preservação. (BRASIL, 1988, Art. 216)

É nesse contexto que as memórias difíceis relacionadas ao período da ditadura militar, iniciada com o golpe de 1964, entram na pauta dos órgãos de preservação do patrimônio no Brasil, sob a forma de tombamentos de lugares de memória de repressão.

\section{Reconhecimento de valor cultural: lugares de memória difícil na cidade de São Paulo}

Considerando que, mais recentemente, há uma tendência de ampliação dos estudos sobre as memórias difíceis no campo da preservação do patrimônio cultural, cuja abordagem ainda é pouco explorada, o presente artigo trata do reconhecimento dos lugares de memória difícil, relacionados ao período militar, pelos órgãos de preservação na cidade de São Paulo, buscando identificar os valores a eles atribuídos no processo de tombamento.

Uma das ações de preservação do patrimônio cultural pelos órgãos competentes é o reconhecimento do valor cultural de um determinado bem.

Após a identificação de um bem com interesse de preservação cultural, por meio de estudos ou de inventário, o órgão de preservação reconhece o valor cultural do bem através de sua proteção legal: o tombamento, no caso do bem material, $\mathrm{e}$ o registro, no caso do bem imaterial.

Interessa-nos, assim, apontar os valores atribuídos pelos órgãos de preservação do patrimônio atuantes na cidade de São Paulo com relação aos lugares de memória difícil relacionados à ditadura militar. $O$ intuito é, através da análise das resoluções de tombamento, documento em que se explicitam os valores atribuídos ao bem protegido, a partir dos seus "considerandos" iniciais, entender a valoração relacionada às memórias 


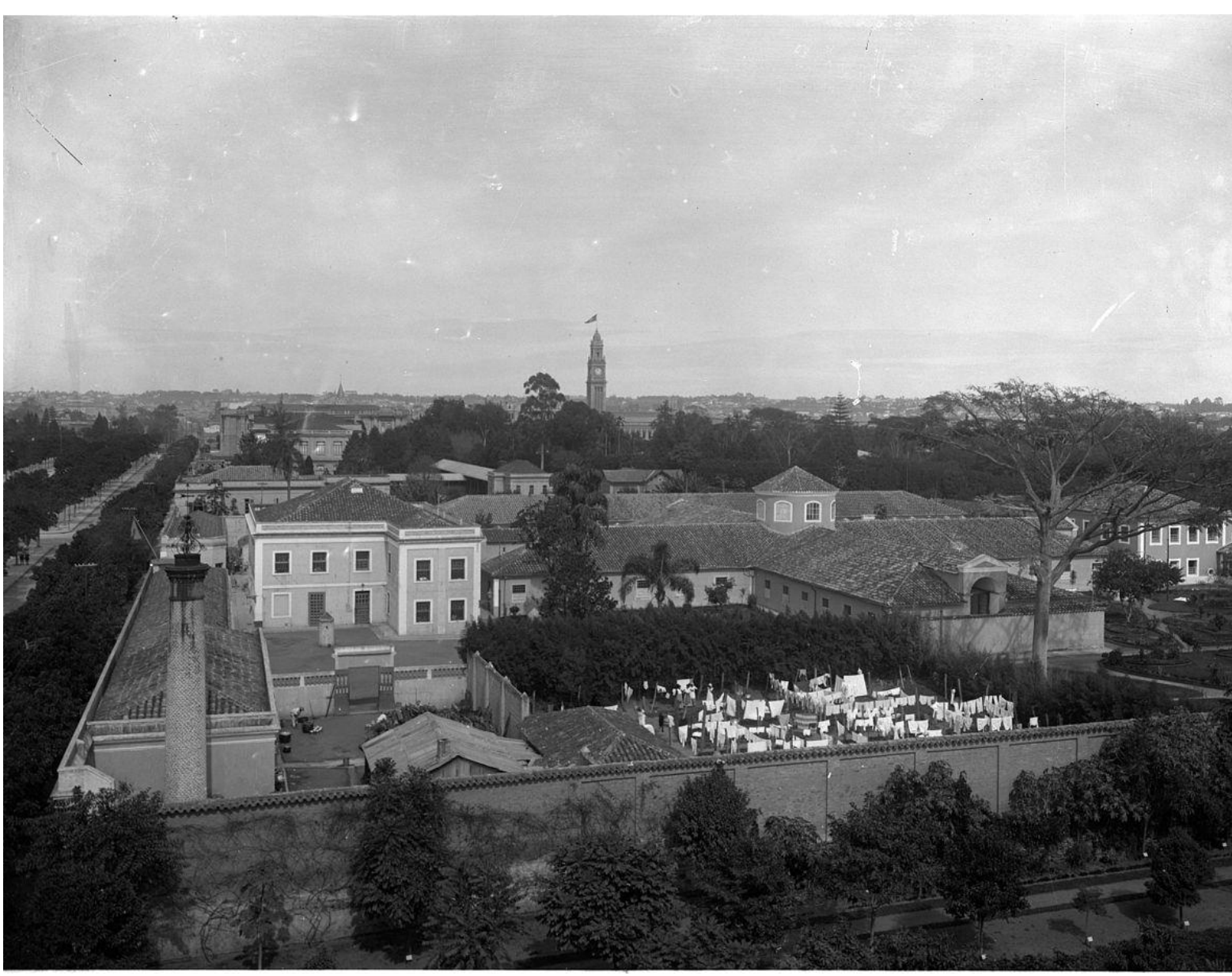

Figura 3. Memorial da Vala de Perus, s/d. Fonte: Acervo dos Autores. difíceis, o que justifica, em última instância, a sua proteção nesse contexto de mudança de visão da sociedade. Como mencionado anteriormente, a década de 1980 foi marcada pela ampliação do conceito de patrimônio não mais restrito a bens de valor excepcional, sendo incorporados, ainda, bens de natureza imaterial, intangível. Os primeiros casos de tombamentos relacionados às memórias difíceis ocorreram neste período. $O$ tombamento do Portal de Pedra do Presídio Tiradentes, efetivado em 1985 pelo órgão estadual de preservação de São Paulo, o Conselho de Defesa do Patrimônio Histórico, Arqueológico, Artístico e Turístico (Condephaat), foi considerado inédito do ponto de vista da justificativa conferida ao tombamento.

\section{O arco do antigo Presídio Tiradentes}

O Presídio Tiradentes (Figura 3), considerado local emblemático de repressão ditatorial na cidade de São Paulo, foi criado em 1825, como cadeia pública, denominada Casa de Correição. Localizado à Avenida Tiradentes e próximo à Pinacoteca do Estado de São Paulo, na região central da cidade.

Os edifícios que compunham o antigo presídio passaram por uma série de usos durante aproximadamente dois séculos de existência, destacando-se como carceragem de presos políticos, tanto no período do Estado Novo, quanto na ditadura militar, principalmente após 1968. Em 1935, 


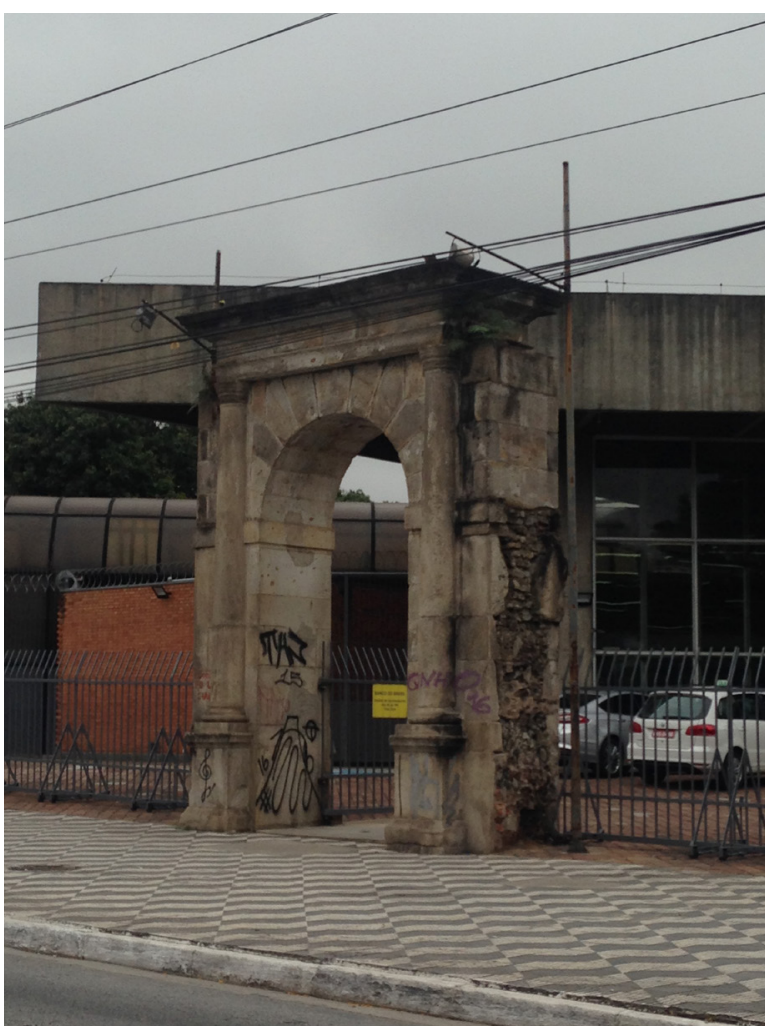

Figura 4. Portal de pedra, em arco, remanescente do antigo Presídio Tiradentes, 2018. Fonte: Acervo dos Autores. o espaço tinha se transformado em Casa de Detenção, e, em 1972, com superlotação e danos físicos, o edifício foi desativado e demolido devido às obras do metrô, dando lugar também a uma agência da Caixa Econômica Estadual e ao Teatro Franco Zampari, da emissora de televisão TV Cultura. Na época houve, inclusive, uma vistoria que detectou que o prédio poderia desabar a qualquer momento. Neste contexto, os presos tiveram que ser transferidos, sendo que alguns foram para o Presídio do Hipódromo e outros para o Presídio do Carandiru. Após a demolição do edifício, restou somente o arco da entrada do antigo presídio, construído em 1930 (Figura 4).

Em 1985, o Condephaat tombou o arco remanescente da demolição do ex-presídio Tiradentes - denominado de Portal de Pedra pelo Conpresp -, como testemunho do antigo presídio, atribuindo-lhe valor pelo caráter histórico da violência institucionalizada que ele simboliza. $\mathrm{O}$ pedido de tombamento foi feito no ano anterior pelo Sindicato de Jornalistas Profissionais no Estado de São Paulo, com o apoio de organizações da sociedade civil e de direitos humanos que alegaram a necessidade de preservação da história política no Brasil através de um monumento que representasse o passado de repressão estatal e as manifestações de resistências.

Marly Rodrigues (2000, p. 101) endossa essa argumentação, citando um trecho do processo de tombamento do Condephaat em que se afirma o intuito de manter a "memória de todos aqueles que, durante toda a história do Brasil, se colocaram ao lado do povo na luta contra o arbítrio e a opressão".

A Resolução de Tombamento SC 59/85, do CONDEPHAAT, datada de 25 de outubro de 1985 e publicada no Diário Oficial em 26/10/85, aponta o valor memorialístico atribuído ao remanescente:

Artigo $1^{\circ}$ - Fica tombado como bem cultural de interesse histórico o arco remanescente da demolição do ex-presídio Tiradentes, localizado na Avenida Tiradentes esquina com a Praça Fernando Prestes, nesta Capital, pelo valor simbólico que representa na luta contra o arbítrio e a violência institucionalizada em nosso país em passado recente.

Atribuiu-se, assim, um valor simbólico que representa, por um lado, a violência institucionalizada, por outro, representa o outro lado da moeda, ou seja, simboliza a luta contra o arbítrio. O lugar de memória difícil tem uma natureza muito particular: ao mesmo tempo em que é testemunho da violência, da opressão, também representa um valor ético de consciência, a luta contra o arbítrio que deve nos lembrar que isso jamais pode voltar a acontecer. Valor afetivo e valor ético estão ali presentes, e não tanto os valores pragmáticos, cognitivos e formais definidos por Meneses (2009). 
Já no âmbito do município, o remanescente do presídio foi tombado através da Resolução $n^{\circ}$ 05/CONPRESP/1991, que tombou ex-offício 89 bens culturais já reconhecidos pelo Condephaat e pelo Iphan, incluindo o "Portal de Pedra, em forma de arco - Avenida Tiradentes, esquina com a Praça Fernando Prestes - Luz".

Importante lembrar que, embora o DPH, que faz parte do sistema municipal de preservação, tenha sido criado em 1975, o Conselho Municipal de Preservação do Patrimônio Histórico, Cultural e Ambiental da Cidade de São Paulo (Conpresp) foi criado somente em 1985, sendo que o primeiro tombamento municipal foi realizado três anos após a sua criação, aproximadamente vinte anos após a criação do Condephaat e cinquenta anos depois do Iphan. Devido a esse hiato de tempo, o Conpresp resolve tombar ex-offício os bens de interesse de preservação para a cidade que já haviam sido protegidos pelos outros órgãos, pois não havia sentido reestudar os bens já amplamente reconhecidos enquanto patrimônio cultural.

Em 1985, de acordo com Janaina Teles (2015, p.201), na data em que se completava 10 anos do assassinato do jornalista Vladimir Herzog, foi instalada no Portal de Pedra uma placa de bronze que dizia: "a todos os homens e mulheres que, no Brasil, ao longo da História, lutaram contra a opressão e a exploração - pela liberdade".
Diante dessa iniciativa, o portal com a placa foi visitado por anos por familiares de ex-presos políticos. Contudo, a placa foi roubada e não se sabe se foi pelo fato de ser de bronze ou por reação dos que se opunham a essa homenagem. Atualmente, o portal continua sem qualquer referência à sua história e a maior parte das pessoas que passa pelo local não tem a menor ideia do que ali aconteceu. Assim sendo, ainda que se constitua hoje como um monumento simbólico, não há no local qualquer informação dessa memória que deveria ser evocada. É evidente que as ações de preservação do patrimônio não devem se limitar ao tombamento. O reconhecimento de valor sem a devida transmissão do significado do bem cultural juridicamente protegido carece de sentido:

A despeito dos esforços de preservação do Portal do Presídio Tiradentes [...] o local que o abriga volta à sua condição de sombra do passado e ruína "invisível" para a maioria da população. (TELES, 2015, p.204)

\section{O antigo DOPS}

O tombamento do Departamento de Ordem Política e Social da Secretaria de Segurança Pública do Estado de São Paulo (DOPS), conhecida por ser "uma das polícias políticas mais truculentas do país, principalmente durante o regime militar" (MEMORIAL DA RESISTÊNCIA, s/d, s/p), foi concluído na década de 1990. 
Localizado na região da Luz, o prédio foi inaugurado em 1914, sendo projeto do escritório do arquiteto Francisco de Paula Ramos de Azevedo, para ser sede administrativa da Estrada de Ferro Sorocabana, funcionando também como estação para embarque e desembarque de passageiros. Foi construído em estilo eclético, baseado na arquitetura inglesa do século XIX. Já em um segundo momento, de 1940 a 1983, abrigou o Departamento Estadual de Ordem Política e Social (DEOPS) - que, mais tarde, passaria a se chamar Departamento de Ordem Política e Social (DOPS) -, e atualmente destina-se parte à Estação Pinacoteca, vinculada à Pinacoteca do Estado, e parte ao Memorial da Resistência.

Em 1939, o edifício passou por reformas para se tornar sede do DEOPS e lugar para repressão de movimentos políticos e sociais, tanto no Estado Novo, quanto, mais tarde, no período da ditadura civil-militar com o golpe de 1964. Diversos crimes relacionados à tortura e ocultamento de corpos foram cometidos no DOPS, tendo esse órgão sido responsável pela prisão de figuras importantes da política brasileira. A partir de 1983, o DOPS foi extinto e o edifício passou a pertencer à Secretaria Estadual da Cultura.

O processo de tombamento estadual do edifício teve início em 1976 e só foi concluído em 1999. No início, esse processo de tombamento $\left(n^{\circ}\right.$ 20151/76) referia-se à antiga Estrada de Ferro Sorocabana e acabou sendo arquivado, por ausência de material de estudo. Já em 1980, o edifício foi incluído, de acordo com o processo $\mathrm{n}^{\circ}$ 24506/86 do Condephaat, como parte da mancha urbana dos Campos Elíseos com interesse de preservação.

De acordo com a Resolução de Tombamento SC 28/99, do CONDEPHAAT, datada de 08 de julho de 1999 e publicada no Diário Oficial em 09/07/99, assim foi descrito o conjunto tombado:

Artigo $1^{\circ}$ - Fica tombado como bem cultural de interesse para memória social paulista o edifício localizado na Praça General Osório n 66, 88, 120 e 136, o "antigo DOPS", construído para abrigar armazéns da Estrada de Ferro Sorocabana, foi ocupado parcial e temporariamente pela direção da mesma empresa até o término das obras da Estação Júlio Prestes, de 1951 a 1953, o do estado e, em seguida, pelo DOPS, Departamento de Ordem Política e Social da Secretaria de Segurança Pública do Estado de São Paulo. Foi projetado pelo Escritório de Ramos de Azevedo, sua importância arquitetônica é grande e decorre principalmente do seu partido arquitetônico. O espaço é definido de forma racional e organiza os ambientes, amplos, entre as prumadas verticais de circulação. Os sistemas estruturais adotados associam elementos modulares em ferro às duas torres de alvenaria portante $e$ resolvem tecnicamente o espaço pretendido. No conjunto das celas, produto da ocupação dos edifícios pelo DOPS, reside parte significativa do seu valor histórico. Tal conjunto será preservado juntamente com os elementos originais do projeto. 


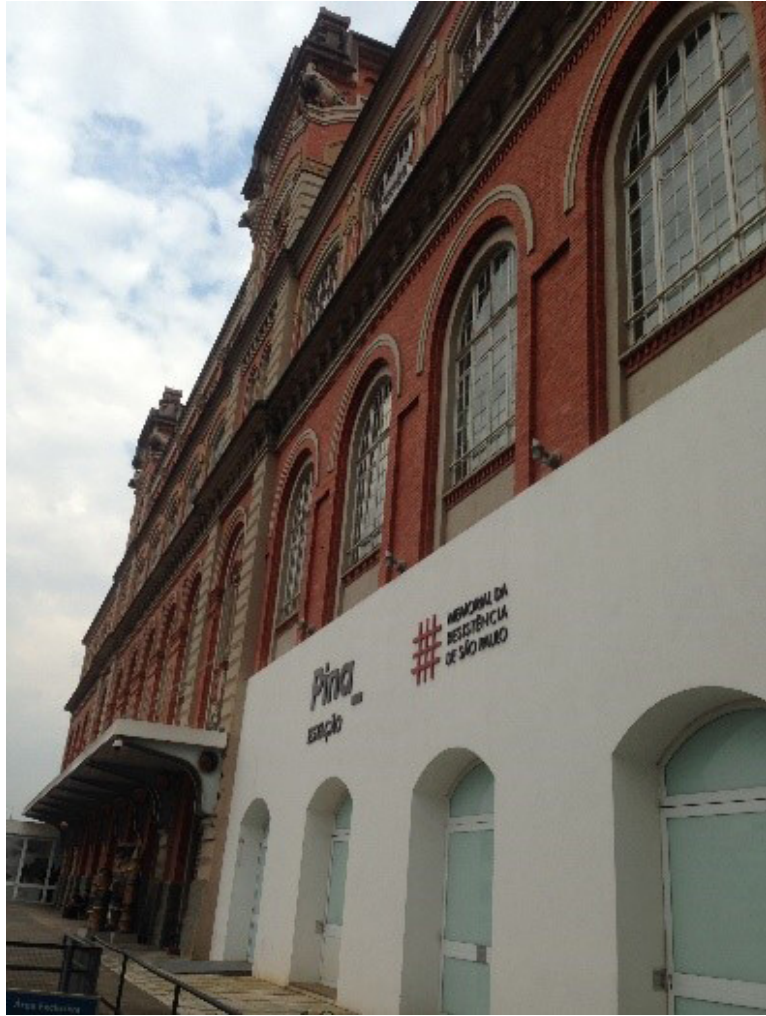

Figura 5. Memorial da Resistência e antigo DOPS, 2018. Fonte: Acervo dos Autores.
5. Informação dada pelo arquiteto Walter Pires, do DPH, no dia $28 / 01 / 2019$.
Diferente dos tombamentos do Portal de Pedra do Presídio Tiradentes e do conjunto do antigo OBAN DOI-CODI, que foram tombados devido, apenas, a sua memória política, sendo que, neste último caso, os edifícios não apresentam qualquer qualidade arquitetônica relevante, o tombamento do edifício do DOPS, apesar de ter sido lugar de memória traumática, está atrelado também à qualidade da arquitetura da antiga Estação Sorocabana. Antes mesmo da Resolução de Tombamento fazer menção ao valor histórico e da memória do edifício, este é valorizado pela arquitetura, o que difere do reconhecimento de valor do conjunto da OBAN e DOI-CODI analisado anteriormente. Por outro lado, é interessante o fato de que a denominação do bem cultural, estabelecida na Resolução de Tombamento, não seja a de "antigos armazéns da Estrada de Ferro Sorocabana", e sim a de "edifício do antigo DOPS": com efeito, o documento indica que a Resolução Condephaat SC 28/99 "dispõe sobre o tombamento do edifício do antigo DOPS". Isto por si só marca uma diferença importante com relação aos valores envolvidos na proteção do bem, ainda que a sua descrição mencione timidamente o valor histórico traduzido no conjunto de celas do antigo DOPS, lugar de grande repressão aos presos políticos que por lá passaram.

No que diz respeito à esfera municipal, o edifício foi inicialmente protegido, na década de 1970, como Z8-200, zona especial de preservação do patrimônio, e integra o processo de abertura de tombamento de todas as Z8-200, indicado na Resolução n 44/CONPRESP/1992. O tombamento definitivo do imóvel ainda não foi concluído, e provavelmente será encaminhado em breve ao Conpresp, com proposta de proteção ex-offício de tombamento realizado pelo Condephaat (informação verbal ${ }^{5}$ ).

Desde 2009, parte do edifício é ocupado pelo Memorial da Resistência (Figura 5), no intuito de preservar as memórias difíceis relacionadas ao período de repressão política no Brasil, por meio de programas educacionais e exposições que remetem a esse passado. O Memorial assim se define:

Membro Institucional da Coalizão Internacional de Sítios de Consciência, uma rede mundial que agrega instituições constituídas em lugares históricos dedicados à preservação das memórias de eventos passados de luta pela justiça e à reflexão do seu legado na atualidade. (MEMORIAL DA RESISTÊNCIA, s/d, s/p)

Infelizmente o reconhecimento de valor por parte dos órgãos de preservação não foi suficiente para evitar as reformas realizadas nas celas em 2002 e que descaracterizaram o espaço, inclusive com o apagamento das inscrições feitas pelos presos que lá estiveram:

A reforma promovida pelos governantes fez desaparecer as quatro celas solitárias, as duas celas coletivas e a carceragem do presídio do DEOPS/SP. Nas celas que sobreviveram a essa 


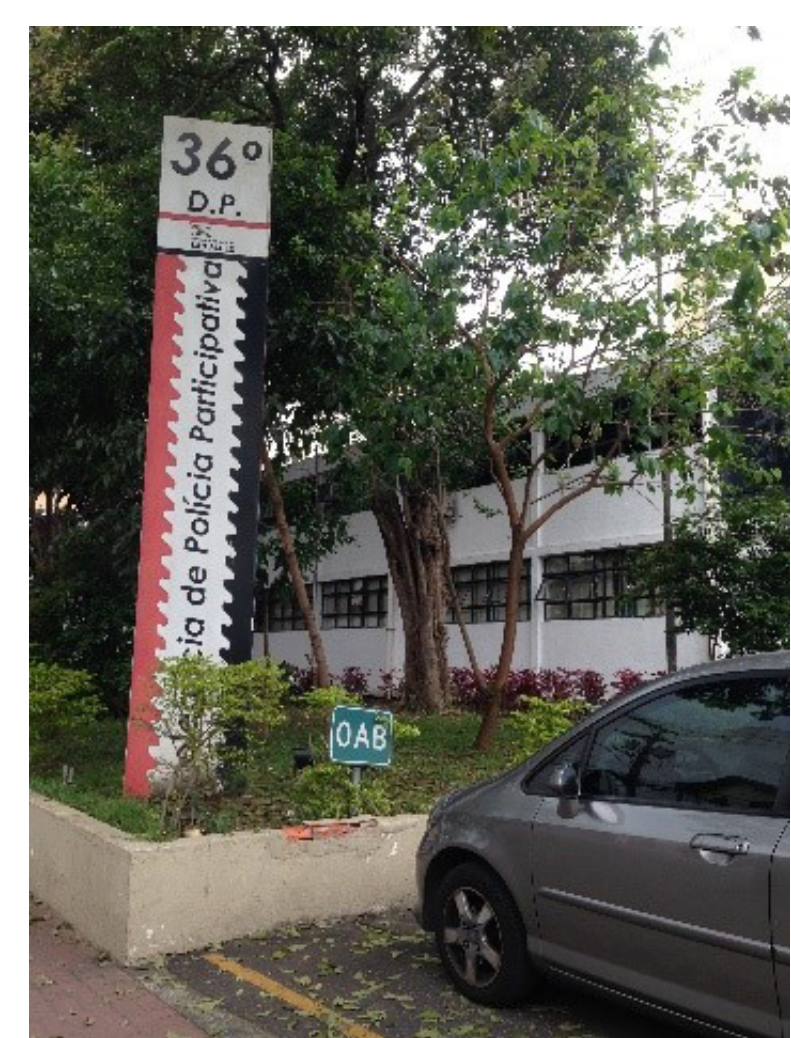

Figura 6. Antiga sede do DOI-CODI, atual $36^{\circ}$ Distrito Policial 2018. Fonte: Acervo dos Autores. reforma desapareceram os diminutos banheiros e as inscrições feitas pelos presos nas paredes e portas, ao longo de toda a história do local. Esses documentos presenciais de personagens ativos da História foram raspados e repintados de modo a não permitir nenhum resquício de lembrança do período. (SEIXAS; POLITI, 2009, p. 200)

É evidente o conflito entre aqueles que tentam apagar a memória do lugar e os que defendem a legitimação das narrativas das vítimas do regime militar.

O Memorial da Resistência tornou-se um espaço de múltiplas ações culturais e educacionais que discutem o passado da ditadura, das violações aos direitos humanos, bem como dos movimentos de resistência, a partir do enfrentamento do trauma e da participação popular para a construção de uma nova história, mais justa e digna. Nesta direção, foi fundamental a participação do Fórum Permanente de ex-Presos e Perseguidos Políticos do Estado de São Paulo junto ao poder público, que, desde 2006, luta pela necessidade de outro olhar para esse lugar (MEMORIAL DA RESISTÊNCIA, s/d, s/p).

O caso do Memorial da Resistência - antes chamado inapropriadamente de Memorial da Liberdade -, com a contribuição de grupos como o Fórum acima citado - é um exemplo de como as políticas públicas podem ir além da ação do tombamento, na busca de preservação da memória social.

\section{O conjunto das antigas instalações da OBAN} e DOI-CODI

Localizado no bairro de Vila Mariana, o conjunto das antigas instalações da Operação Bandeirante (OBAN) e do Destacamento de Operações (DOI), subordinados ao Centro de Operações de Defesa Interna (CODI) (Figura 6), órgão da organização clandestina do Estado, não possui atributos arquitetônicos relevantes, porém o conjunto foi tombado, mais recentemente, pela importância da memória a ele vinculada, conforme expressa a sua Resolução de Tombamento, considerando:

- Que os edifícios que abrigam o DOI-CODI constituem lugar de memória da repressão e da resistência à Ditadura Civil-Militar no Brasil entre 1964-1985;

- Que os edifícios representam a institucionalização do terrorismo de Estado. (CONDEPHAAT, RES. SC 25/2014)

Nesse tombamento, a atribuição de valor é conferida ao lugar de memória da repressão e da resistência, não se tratando de valor relacionado aos aspectos estéticos das edificações, considerando que são desprovidas de qualquer elemento ou qualidade arquitetônica e/ou artística. $\mathrm{O}$ tombamento justifica-se por representar a violência do Estado, através do suporte material dos edifícios:

- Que representam testemunho material da história política recente; 
- Que se trata de lugar simbólico de violação dos Direitos Humanos e privação de liberdade durante o período da Ditadura Civil-Militar;

- Que os edifícios e espaços ali remanescentes são o suporte físico à memória da repressão $\mathrm{e}$ da resistência; [...] (CONDEPHAAT, RES. SC 25/2014)

A Resolução também destaca a necessidade de reparação e preservação do passado por meio de uma construção pública da verdade que procure identificar estruturas e instituições de violação aos direitos humanos e cita a importância da Comissão Estadual de Ex-Presos Políticos como reconhecimento e legitimação.

Três anos depois do tombamento pelo Condephaat, o conjunto da OBAN e do DOI-CODI também foi tombado ex-offício pelo conselho municipal de preservação, o Conpresp (Resolução $n^{\circ}$ 10/2017).

De acordo com Deborah Neves, técnica da Unidade de Preservação do Patrimônio Histórico da Secretaria da Cultura do Estado de São Paulo, o estudo de tombamento "foi paradigmático ao entender aquele como um local em que crimes foram cometidos e que [...] deveria ser tratado como prova material em investigações que estão em andamento na Justiça Federal" (NEVES, 2018, p.175).
Segundo Neves (2018), a metodologia dos estudos de tombamento envolveu uma série de fontes históricas associada a estudos de casos similares na Argentina e na Alemanha, que possibilitaram um estudo que privilegiou o bem como um lugar essencial para preservação da história recente de violação aos direitos humanos. Além disso, a decisão foi tomada em 2014, momento em que completavam 50 anos do Golpe Civil-Militar de 1964, o que representava, para a historiadora, uma reparação simbólica e uma responsabilidade com a verdade.

O DOI-CODI simboliza um dos maiores sítios de perseguição e tortura dos opositores políticos da época. O tombamento do conjunto ainda enfrenta desafios no que diz respeito ao uso que será dado ao edifício, que hoje abriga o $36^{\circ}$ Distrito Policial da Polícia Civil de São Paulo. Existe, atualmente, um conflito entre o Núcleo de Preservação da Memória Política, que solicita que seja instalado no lugar um memorial com cunho educativo através da preservação da memória da ditadura; o Condephaat, que defende a abertura do edifício à visitação pública; e a vizinhança local que, juntamente com a Polícia Civil, são contra a desativação do edifício em prol do memorial, alegando a necessidade de segurança no bairro. O exemplo do DOI-CODI apresenta, assim, os dilemas e enfrentamentos que ocorrem em lugares de memória dolorosa. 


\section{Considerações finais}

Os exemplos acima analisados não guardam nada em comum do ponto de vista arquitetônico, mas o que os une é a sua relação com eventos traumáticos relativos a um recorte muito específico, que é o da repressão e da violação de direitos humanos no período republicano, especialmente o da ditatura civil-militar iniciada com o golpe de 1964. Verifica-se que nas últimas décadas existe uma maior preocupação com o enfrentamento de memórias traumáticas e é a partir do processo de redemocratização do país que os lugares de memórias difíceis ganham destaque.

$\mathrm{O}$ artigo procurou abordar conceitos, dilemas e questões relacionados às memórias difíceis e aos seus lugares de memória, destacando a atualidades desses temas, que nos remetem aos testemunhos de eventos dolorosos, mas que estão também vinculados aos esforços de resistência daqueles que vivenciaram situações violentas. Lugares de memória difícil e de resistência que se tornam, assim, lugares de consciência em busca de um presente e de um futuro mais justos. É nesta direção que a preservação desses lugares de memória guarda especificidades que merecem ser aprofundadas.

A preservação do patrimônio cultural, na atuação dos órgãos de patrimônio, abrange um conjunto de ações que se inicia com a identificação e o chamado reconhecimento, através do tombamento - ou do registro, no caso do patrimônio imaterial -, dos valores que se atribuem aos bens culturais. Evidentemente essas ações iniciais não são suficientes para garantir a salvaguarda dos bens culturais, que deve ser completada por procedimentos de conservação do bem e de valorização junto à sociedade. Pretendeu-se, neste artigo, identificar os valores atribuídos pelos órgãos estadual e municipal de preservação do patrimônio em São Paulo, em três casos emblemáticos de lugares de memória difícil na cidade, com o objetivo de mostrar como as políticas de preservação foram reconhecendo esse tipo particular de testemunho documental ao longo das últimas décadas.

Os tombamentos do Arco do Antigo Presídio Tiradentes (Condephaat, 1985; Conpresp, 1991), do edifício do DOPS (Condephaat, 1999; Conpresp, abertura de tombamento, 1992) e, mais recentemente, do conjunto da antiga OBAN e DOI-CODI (Condephaat, 2014; Conpresp, 10/2017), bem traduzem as transformações na forma de tratamento do tema desde a década de 1980, o que se percebe na mudança de tom do texto de suas Resoluções. Ainda que esses importantes documentos, que tornam públicos os valores envolvidos na proteção do bem cultural, remetam a valores históricos e simbólicos, verifica-se que as expressões utilizadas nas Resoluções vão se tornando mais diretas e incisivas. 
A saber. No caso da Resolução do Condephaat referente ao tombamento do Arco do Antigo Presídio, fala-se em "violência institucionalizada em nosso país em passado recente", sem, contudo, nomear quem são os agentes envolvidos neste processo. No caso da Resolução do Condephaat relativa ao tombamento do DOPS, tampouco se fala claramente sobre a memória de dor, relacionada aos atos de violência perpetrados naquele lugar, mas apenas se indica o valor histórico do "conjunto das celas, produto da ocupação dos edifícios pelo DOPS". Já no tombamento mais recente, de 2014 (Condephaat) e 2017 (Conpresp), do conjunto da OBAN e DOI-CODI, os termos são outros. Neste caso, clara e contundentemente nomeiam-se os responsáveis por tais violências, relacionando-se, nas Resoluções dos órgãos de tombamento, esses lugares de memórias difíceis à ditadura civil-militar no Brasil entre 1964-1985 e à "institucionalização do terrorismo de Estado" (CONDEPHAAT, RES. SC 25/2014; CONPRESP, 10/2017). A violência do Estado é explicitamente apontada. Sem qualquer eufemismo.

Por um lado, contribuíram para essa mudança as próprias transformações que o campo da preservação experimentou desde a década de 1980, traduzidas, na Constituição de 1988, na ampliação do conceito do patrimônio como referência às manifestações dos distintos grupos da sociedade, deixando de restringi-lo apenas ao histórico, ao artístico e ao material e vinculando-o ao cultural e intangível. Por outro, foram fundamen- tais as ações que procuraram dar voz e legitimidade às vítimas da ditadura, como a publicação do livro Brasil: Nunca Mais, a descoberta da Vala de Perus, a criação da Comissão Especial dos Mortos e Desaparecidos Políticos, além da criação de diversas Comissões da Verdade. Essas iniciativas certamente relacionavam-se à mudança de visão da sociedade e caminhavam em direção à necessidade da "construção pública da verdade" (CONDEPHAAT, RES. SC 25/2014).

As questões apontadas nos estudos de casos apresentados neste artigo indicam, assim, os desafios contemporâneos dos órgãos de preservação no que diz respeito ao reconhecimento e salvaguarda de lugares de memória difícil. $\mathrm{O}$ caminho foi aberto, mas é necessário percorrê-lo a partir do aprofundamento das especificidades de sua própria problemática.

\section{Referências}

ARQUIDIOCESE DE SÃO PAULO. Brasil: Nunca Mais. São Paulo: Editora Vozes, 1985. Série Bairro - História I.

BRASIL. (2007). Comissão Especial sobre Mortos e Desaparecidos Políticos. Direito à memória e à verdade. Brasília: Secretaria Especial de Direitos Humanos, 2007. Disponível em: <http://www. dhnet.org.br/dados/livros/a_pdf/livro_memoria1_ direito_verdade.pdf $>$. Acesso em: 13 set. 2018. 
BRASIL. (1988). Constituição da República Federativa do Brasil: promulgada em 5 de outubro de 1988. Disponível em: <http://www.planalto. gov.br/ccivil_03/constituicao/constituicaocompilado.htm>. Acesso em: 26 set. 2018.

CONDEPHAAT. Conselho de Defesa do Patrimônio Histórico, Arqueológico, Artístico e Turístico do Estado de São Paulo. Resoluções. Disponível em: <http://condephaat.sp.gov.br/benstombados>. Acesso em: 26 set. 2018.

CONPRESP. Conselho Municipal de Preservação do Patrimônio Histórico, Cultural e Ambiental da Cidade de São Paulo. Resoluções. Disponível em: <http://www.prefeitura.sp.gov.br/cidade/ secretarias/cultura/conpresp/legislacao/resoluções/index.php?p=1137>. Acesso em: 08 mai. 2018.

CYMBALISTA, Renato. Lugares de memória difícil: as medidas da lembrança e do esquecimento. In: CYAMBALISTA, Renato; FELDMAN, Sarah; KÜHL, Beatriz (Orgs.). Patrimônio Cultural: memória e intervenções urbanas. $1^{a}$ ed. São Paulo: Annablume: Núcleo de Apoio e Pesquisa São Paulo, 2017, p. 231-236.

DESAPARECIDOS Políticos um capítulo não encerrado da História Brasileira. São Paulo: Instituto Macuco, 2012, v. 1. Disponível em: $<$ http://www.dhnet.org.br/verdade/rn/bibliografia/livro_vala_perus_emmanuel.pdf $>$. Acesso em: 28 set. 2018.
DPH. Departamento do Patrimônio Histórico. 0 direito à memória: patrimônio histórico e cidadania. São Paulo: DPH, 1992.

FERNANDES, José Ricardo Oriá. O direito à memória: análise dos princípios constitucionais da política de patrimônio cultural no Brasil (19882010). Fundação Casa de Rui Barbosa, Rio de Janeiro, s/d. Disponível em: <http://www.casaruibarbosa.gov.br/dados/DOC/palestras/Politicas_Culturais/II_Seminario_Internacional/FCRB_ JoseRicardoFernandes_O_direito_a_memoria. pdf $>$. Acesso em: 10 de set. 2018.

HUYSSEN, Andreas. Seduzidos pela memória: arquitetura, monumentos, mídia. Rio de Janeiro: Acroplano, 2000. Disponível em: <https:// cei1011.files.wordpress.com/2010/08>. Acesso em: 19 jul. 2018.

MENESES, Ulpiano. Os Museus e as Ambiguidades da Memória: A Memória Traumática. Encontro Paulista de Museus - Memorial da América Latina. São Paulo, 2018. Disponível em: <https://www.sisemsp.org.br/wp-content/uploads/2018/08/Ulpiano-Bezerra-de-Meneses.pdf $>$. Acesso em: 28 de jan. 2019.

MIRANDA, Andrea; MELO, Ezilda. O Direito à Memória e à Verdade como Direitos Essenciais ao Processo de Democratização do País. Disponível em: <http://www.publicadireito.com. br/artigos/?cod=29a6aa8af3c942a2>. Acesso em: 10 de set. 2018 .

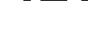


NEVES, Deborah Regina Leal. A persistência do passado: patrimônio e memoriais da ditadura em São Paulo e Buenos Aires. Dissertação (Mestrado em História Social). Faculdade de Filosofia, Letras e Ciências Humanas, Universidade de São Paulo. São Paulo, 2014. Disponível em: <http:// memoria.ides.org.ar/files/2014/10/Neves.pdf>. Acesso em: 07 ago. de 2018.

NORA, Pierre. Memória: da liberdade à tirania. MUSAS. Revista Brasileira de Museus e Museologia, n. 4, 2009. Rio de Janeiro: IBRAM, 2009, p. 6-10. Disponível em: <http://www.museus.gov.br/wp-content/uploads/2012/03/musas20120327.pdf>. Acesso em: 25 set. 2018.

PMSP. Acervos Artísticos e Culturais da Prefeitura de São Paulo. Fotografia do Presídio Tiradentes (1920) de autoria de Aurélio Becherini. Domínio Público. Disponível em: < http://www.acervosdacidade.prefeitura.sp.gov.br/PORTALACERVOS/ ResultadosBusca.aspx?ts=s\&q=cadeia $>$. Acesso em: 02 fev. 2019.

RODRIGUES, Marly. A gestão do patrimônio cultural. Temas de Administração Pública, Araraquara, v. 3, n. 4, 2009. Disponível em: <https:// periodicos.fclar.unesp.br/temasadm/article/ viewFile/6137/4607>. Acesso em: 10 jan. 2019.
. Imagens do passado. A instituição do patrimônio em São Paulo. 1969 -1987. São Paulo: Editora UNESP / Imprensa Oficial, 2000.

SEIXAS, Ivan; POLITI, Maurice. Os elos que vinculam as vivências encarceradas com as perspectivas de comunicação museológica: o olhar dos ex-presos políticos. In: ARAÚJO, M. M.; BRUNO, M.C.O. (Coords.). Memorial da Resistência de São Paulo. São Paulo: Pinacoteca do Estado, 2009.

TELES, Janaina. Ditadura e Repressão: locais de recordação e memória social na cidade de São Paulo. Lua Nova, São Paulo, 96: 191-220, 2015. Disponível em: <http:// www.scielo.br/scielo.php?pid=S0102 $-64452015000300012 \&$ script $=$ sci_abstract $>$. Acesso em: 15 de set. 2018. 